\title{
Supporting and Enhancing Materials Teaching
}

\section{Michelle Hsieh, Granta Design \\ Dr. Arlindo Silva, Granta Design}

Dr. Arlindo Silva is a Senior Materials Education Consultant for Engineering and Design at Granta Design Ltd since January 2012. He had previously been a Professor for 20 years at the Department of Mechanical Engineering, Technical University of Lisbon, in Portugal, with experience in teaching Materials, Design and other Engineering related topics at all levels of higher education. He has a Ph.D. in Mechanical Engineering. He has written three books, published over 100 articles in journals, conferences and book chapters on these topics, and filed over 50 patents with his students on innovative designs. He received the MIT-Portugal Education Innovation Award, 2009. He is an active member of PDMA, ASEE, DS, DRS and SPEE. 


\section{Supporting and Enhancing Materials Teaching}

\section{Introduction}

Materials teaching has been a topic of extensive concern in recent years. Teaching of materials science to materials science students has managed to stabilize somewhat over the years.

However, the same topic taught to students of other disciplines has evolved substantially ${ }^{1}$. It is interesting to note that its breadth has increased dramatically not least because the number of commercially available materials has increased manifold in the last three decades. Teaching about materials has therefore to cope with increasing content, and does so in a context where the competition for space in the engineering curricula by other disciplines is fierce.

Interdisciplinarity is being pursued at both undergraduate ${ }^{2}$ and graduate ${ }^{3}$ levels. The search for interdisciplinary knowledge has long been identified as mandatory for today's technological and innovation leaders. This is one of the goals of INCOSE, the CDIO Initiative and the multiple graduate level programs worldwide. Akay calls in his work for a "renaissance engineer", bridging the gaps between the extremely specialized engineers that were at the root of rapid technological development ${ }^{4}$. Others also acknowledge the need to broaden what have become the traditional boundaries of engineering ${ }^{5}$. The subject of materials is naturally at a crossroads, bridging science and engineering. It feeds science with design requirements that drive research into new materials and at the same time enables breakthrough designs with new materials. It is precisely these characteristics that make the teaching of materials extremely important to the next generation of engineers ${ }^{1}$.

As engineering education in general and materials teaching in particular become broader in scope in todays' higher education institutions, the need for teaching resources increases. Instructors across the globe can enhance their teaching by sharing experiences and supporting each other with various resources. A platform has been created - the Teaching Resources Website - that focuses on the teaching of materials to a broad community of academics.

This growing collection includes, to date:

- 363 - English language exercises

- 226 - Individual resources

- 82 - PowerPoint presentations/lectures

- 51 - Resources contributed by academics in the community

- 31 - Booklets containing exercises with worked solutions

- 8 - Number of countries contributors are from 
The poster will highlight the types of resources available and how they may be accessed by the academic community.

\section{Uses of the Teaching Resources Website}

At the time of writing, the Teaching Resources Website (TRW) is used by hundreds of colleges and universities worldwide. This section explains how the use of TRW, and of its materials education community platform, in established courses for a wide range of higher education programs can contribute to accommodate the inherent breadth of information on the topic with the necessary depth of knowledge required from the students upon completion of the course.

In order to understand the use of the website around the world, a selected number of academics were contacted to let us know how they use it. Their courses range from introductory materials science to capstone design courses, and go on into MSc and PhD levels; but also include the use of TRW in pre-university courses. Figure 1 depicts the countries from where contributions were received. Several case studies of active users of TRW in a number of higher education institutions in several countries are presented and discussed in Silva et al. (2012). The section below offers an overview of their thoughts and uses of TRW.

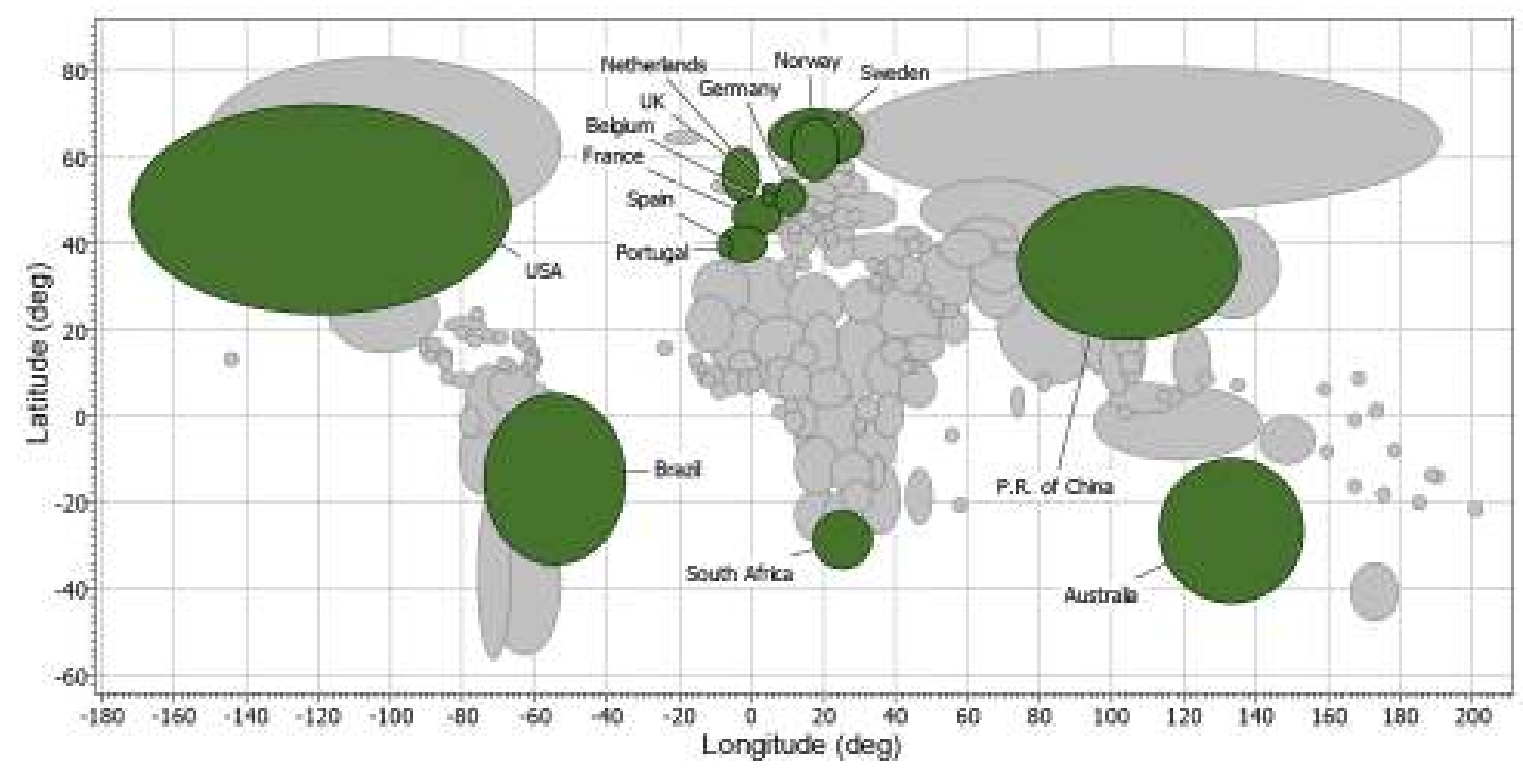

Figure 1. The countries from which institutions contributed to this paper. The map was drawn in CES EduPack with a database of "States of the World" available from the Teaching Resources Website. 
The extensive resources available to academics through TRW are often not used stand-alone. Academics explained how they combine them with their own material, adapt them to suit their course, the level of their students, but also to suit their teaching approach. For example, slides and figures presented in class may sometimes come from TRW's own or contributed resources, with some modifications to fit with the style of teaching and language of the professor. The TRW contents may also be used and modified by the same professor for use in exams; with for example the use of a material property chart, especially built for that purpose, in which the students need to perform some calculations and decide what is the best material for a given application, with a set of objectives, requirements, constraints and free variables.

One reoccurring comment from the case studies can be illustrated with the following: "I personally feel that the teaching resources offered on [the] website have been really supportive for my lecture preparation and students guidance."

Another way in which TRW supports academics is through an extensive portfolio of exercises. Academics' feedback highlights how ready-made exercises and projects, that are then personalized to their teaching, help them develop and improve the course, but also allow more actual teaching time otherwise spent on course development. Some of the content is even given to students as self-study materials to complement other traditional resources. 'Visual aids' is a last main aspect that academics gave feedback on. They felt those, especially the poster charts, which support the teaching for explaining concepts during the laboratory classes.

From these case studies, it seems TRW inspire academics to develop and improve their courses, by using the resources available and to inspire many other academics by contributing with their own resources to TRW.

\section{Subjects Covered}

The Teaching Resources Website contains a collection of hundreds of exercises, teaching aids and background reading material on the topic of materials across many different disciplines and for all years of study.

Introductory and advanced resources have been developed for the following engineering subjects: Materials Science, Industrial Design, Sustainable Engineering, Aerospace Engineering, Mechanical Engineering, Civil Engineering, Architecture, Biomedical Engineering, Energy, Industrial Engineering and Manufacturing.

There is the option to browse by subject, allowing instructors to directly access relevant content. 


\section{Types of Resources}

There is also the option to browse by type, enabling all resources to be viewed.

The Teaching Resources Website includes a variety of resources: exercises and solutions, PowerPoint lectures, white papers, data booklets and teach yourself manuals, videos and recordings, posters and charts, databases and project files, and getting started guides.
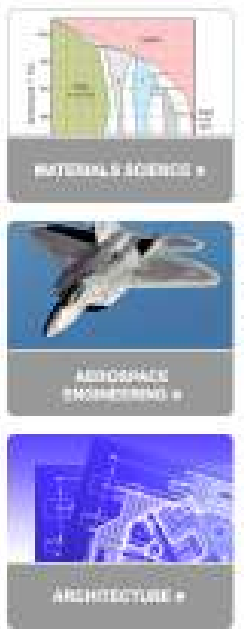
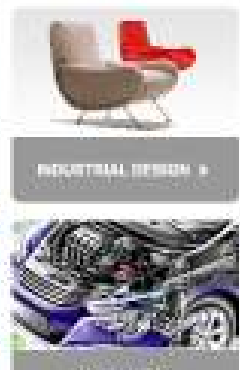

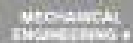

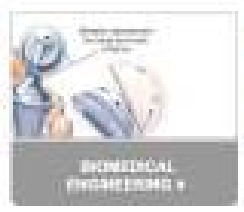

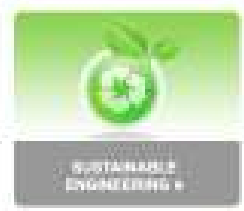
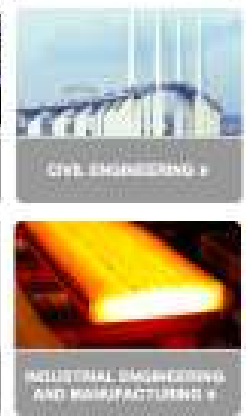
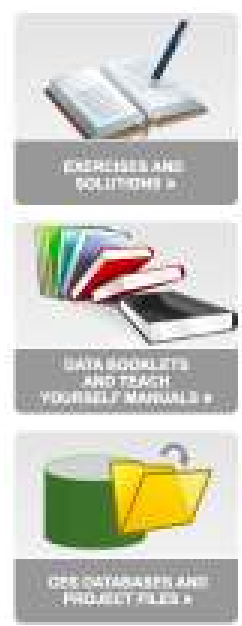
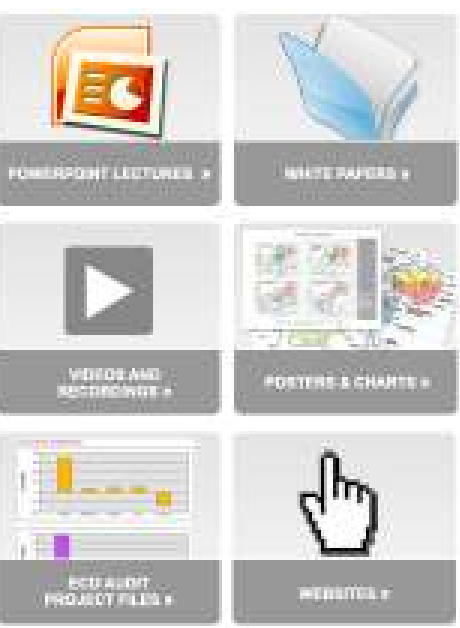

Some example resources:

-Unit 1 covers introductory (freshman/sophomore) years.

-Around 100 exercises available for Eco Design and

-White papers and data booklets (such as Teach Yourself Crystallography) benefit teaching on more complex concepts to advanced (junior/senior) years.

There is also an extensive selection of links to external materials-relevant education websites.

\section{Contributed Resources}

The majority of resources have come from Professor Mike Ashby and colleagues at the University of Cambridge. However, a growing number (25\% at present) have been contributed by educators from other institutions. We have also worked with the UK Centre for Materials Education and DoITPoMS, who focus on the 'Dissemination of IT for the promotion of Materials Science.' 
In terms of the review and verification process for contributed resources to the TRW, the process involves engagement with academics, then receiving their resource(s), and reviewing the information using, if relevant, an external independent feedback process.

The resource information is then written up and formatted to the Teaching Resources Website format. Feedback is provided all year long and the resource is updated accordingly. There is also an annual development meeting involving academics from around the world, which covers the Teaching Resources Website and its contributed resources.

\section{Open Education Resources}

Many of these resources are open access. A number of them have been made available under a creative commons license. These can also be found through the CORE Materials website and on other teaching resource websites in the US and France, as well as on YouTube and Scribd. We are aiming to release further Open Educational Resources during the next 12 months and are looking for project suggestions and possible partners.

\section{Conclusion}

Although the Teaching Resources Website is not intended as the ultimate materials education reference, it nevertheless provides useful information about exciting things being done worldwide and can potentially give you fresh ideas to use in your teaching. 


\section{References}

1. Silva, A., Pereira-Medrano, A.G., Melia, H., Ashby, M., Fry, M. (2012) Materials education: adapting to needs of the 21st Century. 4th International Symposium of Engineering Education, Sheffield, UK, 19-20 July.

2. Bronet, F., et al. (2003) Product Design and Innovation: Evolution of an Interdisciplinary Design Curriculum. International Journal of Engineering Education, 19(1): p. 183191.

3. Silva, A., Henriques, E., Fontul, M., Faria, L. (2009) On some innovative aspects of the EDAM MIT-Portugal Program: the Lisbon perspective. 2nd International Symposium on Engineering Systems, June 15-17, MIT, Cambridge, Mass.

4. Akay, A. (2008) A renaissance in engineering PhD education. European Journal of Engineering Education, 33(4): p. 403 - 413.

5. Dym, C.L., Agogino, A.M., Eris, O., Frey, D.D., Leifer, L.J. (2005) Engineering design thinking, teaching and learning. Jour. Engineering Education, January 103-119 